\title{
Gaming Addiction: An Investigation in Italian Adults in Avola
}

\author{
Concetta De Pasquale1, Federica Sciacca², Vania Fronte ${ }^{2}$ \\ ${ }^{1}$ Department of Medical Surgeon Science and Applied Technology, GF Ingrassia, University of Catania, Catania, \\ Italia \\ ${ }^{2}$ Department of Education Science, University of Catania, Catania, Italia \\ Email: depasqua@unict.it, federica.sciacca@hotmail.com, vania.fronte@hotmail.com
}

Received 23 June 2016; accepted 19 August 2016; published 22 August 2016

Copyright (C) 2016 by authors and Scientific Research Publishing Inc.

This work is licensed under the Creative Commons Attribution International License (CC BY).

http://creativecommons.org/licenses/by/4.0/

(c) (i)

Open Access

\section{Abstract}

Introduction: The aim of this study was the exploration of the spread of gambling in adults in Avola, their consequences and the exploration of the typical thoughts, behaviors and beliefs related to gambling. Materials and Methods: The sample consisted of 160 adults, aged between 18 and 78 years recruited in Avola (Sicily, Italy). The materials were constituted by an exploration questionnaire about gambling to investigate the social-demographic characteristics of the players, the game frequency, the control capacity and the motivation to play and a shorter and multidimensional version of gambling attitudes and beliefs survey (GABS-23), a useful diagnostic tool for screening of gambling that explores the dysfunctional beliefs of gambling and allows to evaluate the beliefs, emotions and attitudes among the gamblers. Results: Results showed that more than half of the sample declared to gamble. In accordance with the diagnostic manual of gambling, the "frequency of game", the "time spend in gambling", the consequent "spend money" are indicative indices that discriminate the "social game" from pathological game. For this reason we have find, in our sample, tree categories of gamblers: "problematic gamblers", "regular players" and "casual players". About GABS-23 factors, they showed that all sample believe that behaviors implemented during the gambling affects about it and believe that some strategies increase the probability of win. Also, according with the studies in the literature, the gamblers showed medium-high score in the "chasing" scale. Conclusion: Despite the prevalence of gambling among adults in Avola, there was no presence of pathological disorder, but a small percentage of those who claim to play, play more frequently, play more than three games a week, undertake more than three hours a week and spend between one hundred and one hundred fifty euro a week. Despite this, the reason that drives them to play in "to earn money" and don't indicate the motivation "try the thrill of risk" typical pathological gambler. This phenomenon is frequently normal amongst the non-clinical population but it needs attention in order to prevent and avoid real psychopathological disorder. 


\section{Keywords}

\section{Gambling, Addiction, Adult, Pathological}

\section{Introduction}

In the last few years, gambling is spreading in Italy involving a high number of population, becoming a significant economic and social importance (Sorce, 2013). In Italy there are many factors that have contributed to the increase in the number of gamblers, the different types of games, the diffusion of slot-machine in bars, the growth of the gambling on-line and the capillary diffusion of the places whether to play (La Rosa, 2016).

Donadeo said that everyone at least once in life, we played gambling (Donadeo, 2014) but everyone play gambling differently. There are people more vulnerable than others to develop an addiction due to individual factors, social-demographic factors and factors related to the characteristics of the object from which it depends (Serpelloni, 2013).

The transition from social player, problem gambler to pathological gambler is progressive and is caused by the interaction of different elements that interact with each other (Croce, 2005).

There has been more extensive research on adults gambler. Previous research showed that male is more involved than female in game (National Research Council, 1999; Welte, Barnes, Wieczorek et al, 2002; Volberg, 1994; Gray, 2004). However also women, during the years, are increasing their need to gamble (Gerstein, Volberg, Murphy, Toce, Hoffman, Palmer et al, 1999).

The female gamblers prefer lotteries, bingo (Hing \& Breen, 2001), "gratta \& vinci” (El Guebaly, Patten, Currie, Williams, Beck, Maxwell, \& Wang, 2006) and slot-machine (Delfabbro, 2000). Furthermore they prefer the legal gambling but they don't like bets live (Lesieur \& Blume, 1991).

Males mainly prefer sport bets, the horse racing, and play game cards (Delfabbro \& Winefield, 1996).

The mainly reason that lead the player to gamble is “to earn money” (Nower \& Blaszczynski, 2010; De Rita, Zucconi, Bono, \& Marzorati, 2009).

Gambling, the emotions and feelings that can provoke, attracts the individual to develop a gambling addicts (DSM 5, 2014).

Pathological female players refer that they dedicate themselves to gambling as a means of escaping from unsatisfactory and stressful life situations or depression whereas men refer that the urge to gamble doesn't depend on their emotional state.

Starting from this theoretical frame work was conducted a descriptive study to highlight the spread of the gambling among adults in the country of Avola, to detect a possible Gambling addiction and to highlight the attitudes and beliefs of gamblers.

\section{Material and Method}

\subsection{Purpose of Study}

In these last years, due to the increasing diffusion of gambling (Sorce, 2013), multiple betting shops have opened in the Italian territory, which have negative effects on an individual's personal, economic, and social aspects (Picone, 2010). From research conducted by a team of Department "Pathology of dependencies" the Italian territory (Piemonte, Italy) it was shown an increase of gambling in Italy (38.3\%) with a higher frequency in the regions of South Italy (Molise 57.5\%, Campania 51.5\% e Sicilia 50.7\%) (Bastiani, Curzio, Gori, Colasante, Siciliano, Panini, Jarre, \& Molinaro, 2010).

Also from the data obtained by the "customs agency and monopolies" (ADM, 2013) it emerges that Sicily is located in ninth place among other Italian regions, because of costs related to gambling, in particular the province of Syracuse (Sicily, Italy) is located in fifth Sicilian province for the amount of money devoted to gambling (La Rosa, 2016).

Given that, the main purpose of the study was to explore the degree of the diffusion of gambling in the Sicilian territory, with a particular reference to the district of Avola, as well as to explore people's thoughts, behavior and beliefs as far as gambling is concerned. 
We have supposed that:

1) The higher the dependency for gambling, the higher is the conviction in illusory gambling strategies supposed to increase the probability of winning;

2) The higher the dependency for gambling, the higher is the persistence in gambling when you lose or win in a particular gambling session;

3) The higher the dependency for gambling, the higher is the belief that gambling attitudes can increase the chances of winning;

4) The higher the dependency for gambling, the higher is belief in good or bad luck and in superstitions;

5) The higher the dependency for gambling, the higher is the emotional excitement provided by gambling.

\subsection{Measures and Procedure}

The protocol used consists of:

- A questionnaire to analyze the socio-demographic characteristics of the sample, the frequency of game, the main motivations of games and the main games used.

- The shorter and multidimensional version of gambling attitudes and beliefs survey (GABS-23).

\subsection{A Questionnaire to Analyze the Socio-Demographic Characteristics of the Sample, the Frequency of Game, the Main Motivations of Games and the Main Games Used}

The questionnaire, elaborated by Conagga, was used to analyze the phenomenon of gambling. It is divided into two parts: in the first part of the questionnaire, the social-demographic data of the participants are collected; the second part of the questionnaire, composed by nine items, investigates games played, frequency of play, the hours devoted to gambling, the money spent during the week, the capacity to control gambling, financial debts, the motivation that pushes the player to play. The questionnaire allows to distinguish different types of players: "Pathological gamblers", that is gamblers that totally lost the control of their behavior, they play huge expenditure of money, have financial debts, they gamble to try strong emotion and they play to try the thrill of risk. All this seriously compromises his affective, social and labor life; "Problematic gamblers" that is gamblers that gamble for so long, games frequently, gamble more different games, spends a lot of money, they haven’t a control of the game and are more chance to become pathological gambler; "Habitual gamblers" that is gamblers that betting so habitual, assiduously, driven by the desire to achieve an economic leap; and "Casual gamblers” that is gamblers that at least once in life they have gambled. "Non-gamblers” (Conagga, 2008).

\subsection{Shorter and Multidimensional Version of Gambling Attitudes and Beliefs Survey}

The shorter and multidimensional version of gambling attitudes and beliefs survey consisting of 23 items that evaluates the games attitudes, beliefs, emotions and the main characteristics of the gambler.

The original version of the survey was drawn by six Frenchpsychiatrists of "University Hospital of Nantes, France” (Bonjou, Hardouin, Boutin, Gorwood, Le Bouvellec, \& Feuillet, 2003).

The GABS-23 in the Italian version showed a reliability equal to.829.The reliability of instruments were calculated using Cronbach's alpha. Participants were asked to answer indicating their level of agreement with a 4-point Likert scale ( 1 = strongly disagree; 2 = disagree; 3 = agree; 4 = strongly agree).

The GABS-23 is divided into 5 dimensions: Strategies (GABS-S) that is conviction in illusory gambling strategies supposed to increase the probability of winning; Chasing (GABS-C) that is concept of "within-session chasing": Persistent gambling when losing or winning within a particular session of gambling; Attitudes (GABS-A) that is conviction in gambling attitudes thought to increase the probability of winning; Luck (GABS-L) that is belief in good or bad luck and in superstitions; Emotions (GABS-E) that is subjective arousal (emotional excitement) provided by gambling (Bouju, Hardouin, Boutin, Gorwood, Le Bourvellec, \& Feuillet, 2003).

\subsection{Statistical Analysis}

The examination of the statistical significance of results was carried out using the SPSS 22 software (Statistical Package for Social Science).

The reliability of instruments were calculated using Cronbach’s alpha. 


\subsection{Participants}

The sample was composed of 160 adults (83 men and 77 women), aged between 18 and 78 years ( $\mathrm{X}=38.23$; DS $=15.54$ ) recruited in the territory of Avola (Sicily, Italy) in the period between November 2015 and February 2016. The sample was recruited through "random method" so as to be representative of the population.

\section{Results and Discussion}

\subsection{Types of Gamblers}

The $40.63 \%$ of people declares to not play, the $59.38 \%$ is a player. The players are 56 men (58.95\%) and 39 women (41.05\%). The results showed that the game is most popular among players of average age 35 (SD = 14.6).

The $61 \%$ of players has a mean-high educational qualification (35.79\% high school diploma, $25.26 \%$ degree), while the $29 \%$ has a mean-lower educational qualification.

The $34.74 \%$ of players is married, the $63.16 \%$ is single and only the $2.11 \%$ is widower.

The $41.05 \%$ of participants is casual gambler, the $53.85 \%$ is women while the $46.15 \%$ is men. They play less than once a week and chose "game card" (71.79\%), "Gratta \& Vinci” (64.10\%) and "sportive bets" (33.33\%). The $71 \%$ of casual gamblers declares to play to hobby.

The $35.79 \%$ of participants is habitual gamblers, the $35.29 \%$ is women and the $64.71 \%$ is men.

They play once or twice a week and they chose "game card" (85.29\%), “Gratta \& Vinci" (79.41\%) and le "sportive bet” (67.65\%). They declare to play to win (62\%).

The $24.21 \%$ of participants is problematic gamblers, the $21.21 \%$ is women while the $48.48 \%$ is men. They play more than three times a week in different games. They declare to play more than 150 Euros a week (43.48\%). They chose “Gratta \& Vinci” (82.61\%), "lotto e lotteries" (73.91\%) e "sportive bets" (65.22\%). They say to play to win (75\%).

\subsection{Gender and Game}

The results show difference related to gender.

In particular the female that play are the $41.05 \%$ of participants. The $31.58 \%$ prefers to play to "Game Card" and "Gratta \& Vinci" (30.53\%). The 20\% play to "lotto e lotteries". They declare to play less than 10 Euros a week $(17.89 \%)$ and less than one hour a week (25.26\%). The 5.26\% plays more than three hours a week and they play to hobby (46.32\%) or win (27.37\%).

The male that play are the $58.95 \%$ of participants. The $42.11 \%$ declare to play to "game card", the $41.05 \%$ plays to "sportive bet" and the $40 \%$ plays to "Gratta \& Vinci". They spend less than 10 Euros a week (23.16\%), the $10,53 \%$ of them spend $30 / 40$ Euros, the 7,27\% spends more than 150 Eurosa week.

The $28.42 \%$ of gamblers play less than one hour a week, while the $15.79 \%$ plays more than three hours a week. They refer to play to hobby (47.37\%) and win (34.74\%).

Women and men prefer social games as "card" and "sportive bet".

These results oppose to literature results because they show that women prefer games as slot-machine, bingo and video poker and they play to reduce boredom and to placate loneliness (Hing \& Breen, 2001) while our results show that women prefer games as "Game Card", "Gratta \& Vinci” and "Lotto e Lotteries" and they play to "hobby" or "win".

\subsection{Games Motivation}

The results show that gamblers motivations are "win money" (62.11\%), then "hobby" (48.42\%), "push luck" (17.89\%) and "provide the thrill of risk" (7.37\%).

These results confirm literature results because they say that social gamblers play to win and hobby, while pathological gamblers play to seeking new sensations (El Guebaly, Patten, Currie, Williams, Beck, Maxwell, \& Wang, 2006).

\subsection{Use and Control of the Games}

The majority of the gamblers said they play to "game cards" and "Gratta \& Vinci" (73.68\%), "sportive bet" 
(53.68\%), "lotto e lotteries" (45\%).

The on-line game is play by $23 \%$ of the gamblers, despite its continuous diffusion.

The gamblers report a good control of the game but in the $18.94 \%$ of their the game has a negative effect on their lives.

\subsection{GABS-23}

The sample show high level in the dimensions "Attitudes" (GABS-A) $(X=58.33$; SD = 20.73) that is the players strongly believe that gambling attitudes can increase the chances of winning and in the dimension "Strategies" (GABS-S) $(X=48.95$; $S D=22.96)$, that is the players are convinced that there are illusory gambling strategies that increase the probability of winning and mean-high level in the dimension "Luck" (GABS-L) (X = 51.38; $\mathrm{SD}=26.54$ ) that is the players believe in good or bad luck and in superstitions.

In particular the sample is divided in gamblers and non-gamblers. Gamblers show high level in dimension GABS-A ( $\mathrm{X}=53.33$; $\mathrm{DS}=21.12$ ), dimension GABS-S $(\mathrm{X}=42.89$; $\mathrm{DS}=23.5)$, dimension GABS-L $(\mathrm{X}=38.94$; $\mathrm{DS}=23.86)$ and in the dimension "Chasing" GABS-C $(X=34.04$; $\mathrm{DS}=28.65)$ that is gamblers strongly believe that details attitudes, strategies affect the chances of winning and they are "trapped in the game", continue to gamble when they losing or winning.

Non-gamblers show high level in GABS-A ( $X=18.15$; DS = 16.18) and GABS-S ( $X=12.69$; DS = 19.26), so in the non-gamblers it is the beliefs that the way to behave and illusory strategies may affect the outcome of the game.

The sample shows attitudes and beliefs related to game.

The results show that in problematic gamblers there is significative correlation between gabs dimensions (Table 1).

It is also showed that in habitual gamblers there is significative correlation between gabs dimensions (Table 2).

\subsection{Correlation between Game's Frequency and GABS-23}

The results demonstrate that between game's frequency and GABS-23 there is a significant correlation. In particular in problematic gamblers:

- The higher the dependency for gambling, the higher is the persistence in gambling when you lose or win in a particular gambling session $(r=0.50, p<.005)$

Table 1. Correlation between gabs dimension in problematic gamblers.

\begin{tabular}{cccccc}
\hline & $\mathbf{S}$ & $\mathbf{L}$ & $\mathbf{A}$ & $\mathbf{C}$ & $\mathbf{E}$ \\
\hline $\mathbf{S}$ & 1 & $r=0.74, p<.000$ & $r=0.64, p<.001$ & $r=0.84 p<.000$ & $r=0.90, p<.000$ \\
$\mathbf{L}$ & $r=0.74, p<.000$ & 1 & $r=0.53, p<.008$ & $r=0.82, p<.000$ & $r=0.74, p<.000$ \\
$\mathbf{A}$ & $r=0.64, p<.001$ & $r=0.53, p<.008$ & 1 & $r=0.51, p<.010$ & $r=0.51, p<.010$ \\
$\mathbf{C}$ & $r=0.84, p<.000$ & $r=0.82, p<.000$ & $r=0.51, p<.010$ & 1 & $r=0.92, p<.000$ \\
$\mathbf{E}$ & $r=0.90, p<.000$ & $r=0.74, p<.000$ & $r=0.51, p<.010$ & $r=0.51, p<.010$ & 1 \\
\hline
\end{tabular}

Table 2. Correlation between gabs dimension in habitual gamblers.

\begin{tabular}{|c|c|c|c|c|c|}
\hline 1 & $\mathbf{S}$ & $\mathbf{L}$ & A & C & $\mathbf{E}$ \\
\hline $\mathbf{S}$ & 1 & $r=0.20, p<.001$ & $r=0.57, p<.005$ & $r=0.39 p<.003$ & $r=0.50, p<.001$ \\
\hline $\mathbf{L}$ & $r=0.20, p<.001$ & 1 & $r=0.17, p<.000$ & $r=0.35, p<.001$ & $r=0.46, p<.004$ \\
\hline A & $r=0.57, p<.005$ & $r=0.17, p<.000$ & 1 & $r=0.28, p<.001$ & $r=0.31, p<.001$ \\
\hline $\mathbf{C}$ & $r=0.39 p<.003$ & $r=0.35, p<.001$ & $r=0.28, p<.001$ & 1 & $r=0.85, p<.003$ \\
\hline $\mathbf{E}$ & $r=0.50, p<.001$ & $r=0.46, p<.004$ & $r=0.31, p<.001$ & $r=0.85, p<.003$ & 1 \\
\hline
\end{tabular}


- The higher the dependency for gambling, the higher is the conviction in illusory gambling strategies supposed to increase the probability of winning $(r=0.20, p<.005)$;

- The higher the dependency for gambling, lower is the emotional excitement provided by gambling $(r=0.02$, $p<.005)$

- The higher the dependency for gambling, the higher is the belief that gambling attitudes can increase the chances of winning $(r=0.47, p<.021)$

- The higher the dependency for gambling, the higher is belief in good or bad luck and in superstitions ( $r=$ $0.40, p<.021$ )

These results confirm literature results that show as problematic gamblers play more time than other gamblers and in different games than them, they are trapped in the belief that perseverance to the game will be rewarded and they start to believe that exist game strategies that affect the payout (Donadeo, 2014) but they do not gamble to try strong emotions, typical attitude of the pathological gambler.

In habitual gamblers there isn't significative correlation between game's frequency and Gabs-23 except to:

- Game's frequency and gambling attitudes $(r=-.06, p<.021)$

- Game's frequency and the persistence in gambling. $(r=-.22, p<.001)$

In casual gamblers and non-gamblers there aren't significative correlations between game's frequency and gambling attitudes or beliefs (GABS-23).

\section{Conclusions}

Adults spend more and more time to play with different games as Gratta \& Vinci, lotto, Superenalotto, sportive bet and slot machine. In particular women and men prefer social games as "card" and "sportive bet" but these results don't confirm literature finds because Capitanucci and Carlevaro show that women prefer games as slot-machine, bingo and video poker more than men (Capitanucci \& Carlevaro, 2004).

The sample refers to play to "win money”, "hobby", "push luck” and "provide the thrill of risk".

These results confirm literature finds (co.na.gga-cnca, 2011). In yours study Picone shows that social gamblers play to win money and for hobby, while pathological gamblers play to seeking new sensations (Picone, 2010).

In our study, female and male both play. We divided the sample in four categories according to game's frequency and games practiced in the short period.

All hypotheses didn't confirm. We were confirmed only the following assumptions:

1) The higher the dependency for gambling, the higher is the conviction in illusory gambling strategies supposed to increase the probability of winning;

2) The higher the dependency for gambling, the higher is the persistence in gambling when you lose or win in a particular gambling session;

3) The higher the dependency for gambling, the higher is the belief that gambling attitudes can increase the chances of winning;

4) The higher the dependency for gambling, the higher is belief in good or bad luck and in superstitions.

But the hypothesis has not been confirmed according to which with increasing frequency of the game, increases the emotional excitement provided by gambling.

So in our study, with this sample, we did not find a significant correlation between the frequency of gambling and emotional arousal linked to gambling.

In problematic gamblers, that is those who are no longer able to control the game, start to increasingly devote more time to the game, it increases the frequency of play, increases the amount of money wagered and the game starts to play a primary role in their lives (Lavanco, 2010), the game's frequency is positively correlated with conviction in illusory gambling strategies supposed to increase the probability of winning (GABS-S) and is negatively correlated with belief in good or bad luck and in superstitions (GABS-L) and conviction in gambling attitudes thought to increase the probability of winning (GABS-A).

In habitual gamblers, that is gamblers where the game does not interfere with daily life but represents only a momentary fulfilling experience within the daily routine (Picone, 2010), the game's frequency is negatively correlated with conviction in gambling attitudes thought to increase the probability of winning (GABS-A) and "within-session chasing”(GABS-C).

In casual gamblers, those who, at least once in their lives, have gambled, and non-gamblers there aren’t signi- 
ficative correlations between game’s frequency and gambling attitudes or beliefs.

In conclusion, the results showed that more than half of the sample gamble $(59.38 \%)$. The $15 \%$ of gamblers are problematic gamblers but they aren't pathological gamblers, because they do not meet the diagnostic criteria useful to confirm a gambling addiction (DSM 5, 2014).

This study has allowed us to reflect on gambling diffusion in adult. It needs attention for the prevention to gambling.

It is necessary to intervene immediately in order to avoid that the game becomes a dependency. For these reasons it is necessary to plan a psycho-educational program with gamblers and their family to prevent the damaging consequences to personal, social and economic and to plan projects of information on problem gambling and its pathological consequences.

\section{Limits}

The limitations of this study is: the use of self report questionnaires has a limit as they can invalidate the reliability of the results due to the fact that the participants could answer without being sincere because of their difficulty of accepting their gambling problem, and therefore compromising their "social desirability"; not consider possible social and cultural factors that can influence the results, such us ethnic differences or specific age groups.

We aim to expand our research to adults from other municipalities of Sicily and to deepen the variables until now excluded.

\section{References}

Agenzia delle Dogane e dei Monopoli (2013). Organizzazione, attività e statistica (pp. 87-112).

APA (2014). DSM-5 Manuale diagnostico e statistico dei disturbi mentali. Francesco Cortina Editore.

Bastiani, L., Curzio, O., Gori, M., Colasante, E., Siciliano, V., Panini, R., Jarre, P., \& Molinaro, S. (2010). L'italiachegioca: Uno studio su chi gioca per gioco e chi viene "giocato" dal gioco, Progetto "Dipendenze Comportamentali: Progetto sperimentale nazionale di sorveglianza e coordinamento/monitoraggiodegliinterventi”. Novembre 2010.

Bonjou, G., Hardouin, J. B., Boutin, C., Gorwood, P., Le Bouvellec, J. D., \& Feuillet, F. (2003). Shorter and Multidimensional Version of the Gambling Attitudes and Beliefs Survey (GABS-23). Journal of Gambling Behavior, 30, 349-367.

Capitanucci, D., \& Carlevaro, T. (2004). Guida ragionata agli strumenti diagnostici e terapeutici nel Disturbo da Gioco d'Azzardo patologico. Bellinzona: Hans Dubois.

Co.Na.GGA-CNCA (a cura di) (2011). Ricerca nazionale sulle abitudini di gioco degli italiani.

Croce, M. (2005). Psicologia del giocatore d'azzardo patologico e rischi di criminalità. Rivista della Scuola Superiore dell'Economia e delle Finanze, No. 10, 130-144.

De Rita, G., Zucconi, S., Bono, P., \& Marzorati, M. (2009). Il gioco in Italia: Un mercato ad alto impatto sociale. Quaderni per l'economia, 4.

Delfabbro, P. H. (2000). Gender Differences in Australian Gambling: A Critical Summary of Sociological and Psychological Research. Australian Journal of Social, 35, 145-157.

Delfabbro, P. H., \& Winefield, A. H. (1996). Community Gambling Patterns and the Prevalence of Gambling-Related Problems in South Australia: With Particular Reference to Gaming Machines. Adelaide: Department of Family and Community Services.

Donadeo, C. (2014). Gioco d'azzardo e ludopatia. Dal divertimento alla dipendenza. Hans \& Alice Zevi Editions. Milano.

El Guebaly, N., Patten, S. B., Currie, S., Williams, J.-V., Beck, C. A., Maxwell, C. J., \& Wang, J. L. (2006). Epidemiological Associations between Gambling Behavior, Substance Use \& Mood and Anxiety Disorders. Journal of Gambling Studies, 22, 275-287. http://dx.doi.org/10.1007/s10899-006-9016-6

Gerstein, D., Volberg, R. A., Murphy, S., Toce, M., Hoffman, J., Palmer, A. et al. (1999). Report to the National Gambling Impact Study Commission. Chicago: National Opinion Research Center at the University of Chicago.

Gray, P. B. (2004). Evolutionary and Cross-Cultural Perspectives on Gambling. Journal of Gambling Studies, 20, 347-371. http://dx.doi.org/10.1007/s10899-004-4579-6

Hing, N., \& Breen, H. (2001). Profiling Lady Luck: An Empirical Study of Gambling and Problem Gambling amongst Female Club Members. Journal of Gambling Studies, 17, 47-69. http://dx.doi.org/10.1023/A:1016640332005

La Rosa, F. (2016). Il gioco d'azzardo in Italia. Contributi per un approccio interdisciplinare. Milano: Franco Angeli 
Editore.

Lavanco, G. (2010). Psicologia del gioco d'azzardo. Milano: McGraw-Hill.

Lesieur, H. R., \& Blume S. B. (1991). Evaluation of Patients Treated for Pathological Gambling Treatment Unit, Using the Addiction Severity Index. British Journal of Addiction, 86, 1017-1028. http://dx.doi.org/10.1111/j.1360-0443.1991.tb01863.x

National Research Council (1999). Pathological Gambling: A Critical Reriew. Washington DC: National Academy Press.

Nower, L., \& Blaszczynski, A. (2010). Gambling Motivations, Money-Limiting Strategies, and Precommitment Preferences of Problem versus Non-Problem Gamblers. Journal of Gambling Studies, 26, 361-372.

http://dx.doi.org/10.1007/s10899-009-9170-8

Picone, F. (2010). Il giocod'azzardopatologico. Roma: Carocci Editore.

Serpelloni, G. (2013). Gambling. Verona: Cierre Grafica.

Sorce, V. (2013). Non giocarti la vita. Esperienza di prevenzione, diagnosi e trattamento del gioco d'azzardo patologico. Caltanissetta: Edizioni di solidarietà.

Volberg, R. A. (1994). The Prevalence and Demographics of Pathological Gamblers: Implications for Public Health. American Journal of Public Health, 84, 237-241. http://dx.doi.org/10.2105/AJPH.84.2.237

Welte, J. B., Barnes G. M., Wieczorek, W. F., Tidwell, M.-C., \& Parker, J. (2002). Gambling Participation in the US-Results from a National Survey. Journal of Gambling Studies, 18, 313-337. http://dx.doi.org/10.1023/A:1021019915591

\section{Submit or recommend next manuscript to SCIRP and we will provide best service for you:}

Accepting pre-submission inquiries through Email, Facebook, LinkedIn, Twitter, etc.

A wide selection of journals (inclusive of 9 subjects, more than 200 journals)

Providing 24-hour high-quality service

User-friendly online submission system

Fair and swift peer-review system

Efficient typesetting and proofreading procedure

Display of the result of downloads and visits, as well as the number of cited articles

Maximum dissemination of your research work

Submit your manuscript at: http://papersubmission.scirp.org/ 